\title{
Rescue of mice homozygous for lethal albino deletions: Implications for an animal model for the human liver disease tyrosinemia type 1
}

\author{
Gavin Kelsey, ${ }^{1,6}$ Siegfried Ruppert, ${ }^{1,4}$ Friedrich Beermann, ${ }^{1,5}$ Christina Grund, ${ }^{2}$ Robert $M$. \\ Tanguay, ${ }^{3}$ and Günther Schütz ${ }^{1}$ \\ ${ }^{1}$ Division Molecular Biology of the Cell I and ${ }^{2}$ Division Membrane Biology and Biochemistry, German Cancer Research \\ Center, Heidelberg, Germany; ${ }^{3}$ Laboratoire de Génétique Cellulaire et Moléculaire, Centre de Recherche du Centre \\ Hospitalier de l'Université Laval, Ste-Foy, Québec, Canada
}

Mice homozygous for specific deletions around the albino locus on chromosome 7 die within the first few hours of birth. They have a complex phenotype in liver and kidney, which includes multiple changes in gene expression and ultrastructural abnormalities. On the basis of this phenotype, it was proposed that these deletions remove a regulatory locus, alf or hsdr-1. Recently, we and others showed that the gene for fumarylacetoacetate hydrolase (Fah), an enzyme involved in tyrosine catabolism, was disrupted by the lethal albino deletion $c^{14 C o s}$. The finding that the Fah gene in wild-type mice is highly expressed only in cell types that develop a phenotype in mutants, and the fact that Fah deficiency determines the human liver disease hereditary tyrosinemia type 1 (HT1), suggested that disruption of the Fah gene was responsible for the lethal albino phenotype. To test this hypothesis, we have created lines of mice carrying Fah transgenes. We find that $c^{14 C o s}$ homozygotes which express transgenic Fah are complemented for all aspects of the complex lethal albino phenotype. Moreover, the degree to which the phenotype is corrected depends on the level of transgenic Fah expression. These results unequivocally establish $\mathrm{Fah}$ as the gene mapping at alf/hsdr-1 and prove that the phenotype depends ultimately on the blockage of tyrosine metabolism. Finally, they suggest lethal albino mice as an animal model for HT1.

[Key Words: Albino deletions; transgenic mice; liver-specific gene expression; tyrosine metabolism; hereditary tyrosinemia type 1]

Received August 16, 1993; revised version accepted September 30, 1993.

Systematic mutagenesis experiments in the mouse have provided a wealth of mutations invaluable for the understanding of mammalian development.Particularly useful resources for the identification of developmentally important genes are the clusters of induced mutations recovered around specific loci. Of these, the albino deletion complex on chromosome 7 is perhaps the best characterized phenotypically and molecularly (Rinchik and Russell 1990; Holdener-Kenny et al. 1992). Many of the albino deletions cause recessive lethal phenotypes, such as arrest of development at specific embryological stages or failure to survive beyond birth (Erickson et al. 1968; Russell et al. 1979|. Complementation analyses indicate that the deletion complex defines at least six genes es-

Present addresses: ${ }^{4}$ Howard Hughes Medical Institute, Department of Molecular and Cell Biology, University of California at Berkeley, Berkeley, California 94720 USA; ${ }^{5}$ Swiss Institute for Experimental Cancer Research, Epalinges, Switzerland.

${ }^{6}$ Corresponding author. sential for normal development (Gluecksohn-Waelsch 1979; Russell et al. 1982; Niswander et al. 1989). Here, we are concerned with the phenotype associated with deletions causing neonatal lethality; for the sake of simplicity, we shall restrict the term lethal albino to this phenotype.

The lethal albino phenotype is complex (Kelsey and Schütz 1993), affecting gene expression and cell ultrastructure, but is apparently confined to two cell types: hepatocytes and proximal convoluted tubule cells in the kidney. The aspect that has aroused most interest is the deficiency of key enzymes of gluconeogenesis, the urea cycle, and associated metabolic pathways /GluecksohnWaelsch 1979, 1987; Schmid et al. 1985; Loose et al. 1986; Morris et al. 1988; Ruppert et al. 1990). Hypoglycemia resulting from such enzyme deficiencies might be the cause of death of the newborns (Erickson et al. 1968). It appeared that the expression of a limited number of genes was affected (Gluecksohn-Waelsch 1979), a class normally regulated by gluconeogenic hormones (Ruppert 
et al. 1990). These genes fail to respond to hormonal induction in the mutant liver (Schmid et al. 1985; DeFranco et al. 1988) despite the presence of the glucocorticoid receptor (DeFranco et al. 1991) and components of the cAMP-signaling pathway (Ruppert et al. 1990). On the basis of this phenotype, it was proposed that the lethal albino deletions remove a regulatory locus essential for the perinatal activation of hormone-responsive genes in liver (Gluecksohn-Waelsch 1987; GluecksohnWaelsch and DeFranco 1991). The locus has been named hsdr-1 (hepatocyte-specific developmental regulation- $\underline{1}_{\text {; }}$ McKnight et al. 1989) and alf (albino lethal mutation factor; Ruppert et al. 1990), and is referred to here as alf/hsdr-1. Subsequent findings that the genes for several liver-enriched transcription factors are also down-regulated (McKnight et al. 1989; Gonzalez et al. 1990; Ruppert et al. 1990; Tönjes et al. 1992) have implied a more widespread effect on gene expression than recognized previously. It may be anticipated that a deficit of such factors will impair the induction of hormone-responsive genes.

Simple views of the lethal albino phenotype are complicated by findings that a diverse set of genes are overexpressed (Kelsey and Schütz 1993). The gene for NAD(P)H:menadione oxidoreductase (Nmo-1), an enzyme involved in detoxification of a wide variety of electrophilic xenobiotics (Talalay et al. 1988), is induced potently in liver and kidney (Petersen et al. 1989; Ruppert et al. 1992). The modest induction of other enzymes associated with oxidative detoxification suggests that the affected tissues may be under oxidative stress (Liang et al. 1992). It has been proposed, alternatively, that a negative regulatory locus, coined $\mathrm{Nmo}-1 \mathrm{n}$, responsible for maintaining the normally low level of expression of these enzymes, is removed by the lethal albino deletions (Petersen et al. 1989; Nebert et al. 1990). Other genes found to be markedly overexpressed are associated with responses to growth arrest or DNA damage (Fornace et al. 1989). One of these, gadd153, encodes a member of the CCAAT/enhancer-binding protein (C/EBP) family, CHOP (들 homologous protein), which may function as an inhibitor of C/EBP-like transcription factors (Ron and Habener 1992). A second gene of unknown function, gadd45, is a target for regulation by $\mathrm{p} 53$ (Kastan et al. 1992). In addition, potent overexpression of the early response gene c-fos has been described (Ruppert et al. 1992). Inappropriately high levels of proteins, such as CHOP or Fos, could upset gene regulation in the neonatal liver, owing to their ability to antagonize the function of positively acting transcription factors.

Finally, the lethal albino phenotype has an ultrastructural component. Parenchymal cells of the liver and proximal convoluted tubule cells of the kidney display profound alterations, particularly of the endoplasmic reticulum (ER) and Golgi apparatus, which develop late in gestation (Trigg and Gluecksohn-Waelsch 1973).

In view of the large size of the neonatal lethal albino deletions-the deletion $c^{14 C o s} c^{14 C o s}$, for example, is $\sim 3.8 \mathrm{Mb}$ (Kelsey et al. 1992)-it is conceivable that the removal of more than one gene is responsible for the complex phenotype. The fact that all components of the phenotype are present in the same two cell types, however, would be equally compatible with a single gene defect. As the culmination of efforts to isolate candidate genes for $a l f / h s d r-1$ by positional cloning (Kelsey et al. 1992; Schedl et al. 1992), we and others (Klebig et al. 1992, Ruppert et al. 1992) found that the $c^{14 \operatorname{CoS}}$ deletion disrupted the gene for fumarylacetoacetate hydrolase (Fah). Fah is the final enzyme in the catabolism of tyrosine. Absence of Fah activity could lead to accumulation of highly electrophilic and potentially toxic tyrosine metabolites. Three lines of evidence suggest that deficiency of Fah could determine the lethal albino phenotype. First, the pattern of expression of Fah mRNA in wildtype mice, as determined by Northern blot and in situ analysis, correlates well with the cell types in which the phenotype develops (Ruppert et al. 1992). Second, genetically determined Fah deficiency in humans results in a severe and potentially fatal infant liver disease, hereditary tyrosinemia type 1 (HT1) (Kvittingen 1986; Goldsmith and Laberge 1989). Third, changes in gene expression similar to those that occur in the lethal albino liver could be mimicked in primary cultures of hepatocytes by treatment with the tyrosine metabolite homogentisic acid (Ruppert et al. 1992). Because alf/hsdr-1 was suspected of encoding a regulatory function, the proposal that a metabolic defect could be responsible for the lethal albino phenotype needs to be tested. Accordingly, we have generated $c^{14 C o S}$ homozygotes that express Fah from a transgene. We find that all aspects of the $c^{14 C o S}$ phenotype are corrected by expression of transgenic Fah.

\section{Results}

Expression of transgenic Fah corrects neonatal hypoglycemia and restores viability of $\mathrm{c}^{14 \mathrm{Cos}}$ homozygotes

Two constructs designed to express mouse Fah at high levels in liver and kidney were used for the generation of transgenic mice (Fig. 1). Bg:FAH comprises a $4.7-\mathrm{kb}$ genomic BgIII fragment from the $5^{\prime}$ end of the mouse Fah gene fused to the mouse Fah cDNA at the single BgIII site within exon II. This construct includes sequences underlying the three DNase I hypersensitive sites present on the Fah gene in liver and kidney nuclei that might overlie important regulatory elements (G. Kelsey, unpubl.). A second construct, At:FAH, was based on previous experience that human $\alpha$-1-antitrypsin transgenes are highly and reliably expressed in liver and kidney of transgenic mice (Kelsey et al. 1987; Rüther et al. 1987; Sifers et al. 1987). In At:FAH, the near full-length mouse Fah cDNA was placed under the control of $3.7 \mathrm{~kb}$ of upstream sequences of the human $\alpha$-1-antitrypsin gene. Both constructs contained sequences from SV40 downstream of the Fah cDNA to provide splicing and 3 ' end processing information, and a "tag" for transgenic Fah mRNA.

The two constructs were microinjected separately into 

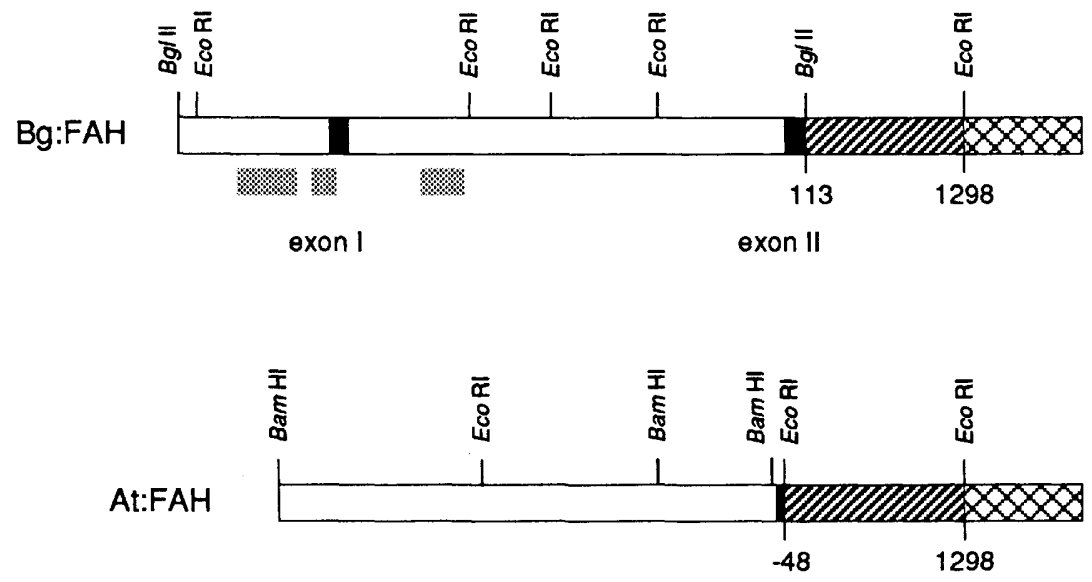

fertilized oocytes from albino (c/c) NMRI/Han mice. Founders were crossed with pigmented carriers of the lethal albino $c^{14 C o s}$ deletion (genotype $c^{14 \operatorname{Cos}} / c^{c h}$ ). Pigmented $F_{1}$ offspring $\left(c / c^{c h}\right)$ were examined for expression of the transgene, and transgenic albino $\mathrm{F}_{1}$ mice $\left(c^{14 \operatorname{Cos}} / c\right)$ were kept for further breeding. Of seven Bg:FAH transgenic lines in which expression of transgenic Fah mRNA was found in liver, two were chosen for complementation of the $c^{14 \operatorname{CoS}}$ deletion. Mice from line 1127 contained $\leqslant 5$ copies of Bg:FAH and expressed transgenic Fah mRNA in newborn liver and kidney at $\sim 50 \%$ of the homozygous wild-type level. In newborn mice of line 1093, a line with $\sim 50$ copies of Bg:FAH, transgenic Fah mRNA was detected at greater than wild-type levels in the liver but none in the kidney. A single At:FAH transgenic line, 921, which had 15-20 copies of At:FAH and expressed transgenic Fah at very low levels in newborn liver, was also analyzed. High levels of transgene expression were not detected in other tissues in any of the lines (data not shown).

Albino $\left\langle c^{14 \operatorname{Cos} / c)} \mathrm{F}_{1}\right.$ carriers of the three transgenic insertions were backcrossed with $c^{14 \mathrm{Cos} / c^{c h}}$ mice, litters were examined for lethalities, and surviving albinos were genotyped at weaning by Southern blot analysis. The albino $\mathrm{F}_{2}$ progeny are either homozygous or heterozygous for the $c^{14 C o S}$ deletion and may or may not have inherited the transgenes. The four possible genotypes were distinguished in EcoRI digests of tail DNA probed with RN.Fd $(B g l)$, a single-copy genomic fragment covering exons IV and $\mathrm{V}$ of the Fah gene (Fig. 2c). RN.Fd(BgI) detects $E c o R I$ fragments diagnostic for either transgene and, because of its proximity to the end of the $c^{14 C o s}$ deletion (Ruppert et al. 1992), detects a 4.8-kb EcoRI fragment specific for the $c^{14 C o s}$ allele and a 6.4-kb fragment for the wild-type allele.

$c^{14 C o S}$ homozygotes surviving because of the inheritance of Fah transgenes were recovered among albino $\mathrm{F}_{2}$ offspring of all three transgenic lines. Hereafter, these transgenic $c^{14 C o S}$ homozygotes are referred to as "rescued." Figure 2 shows the Southern blot analysis of two litters of line 921, and Table 1 is a compilation of the survival data for albino $F_{2}$ and $F_{3}$ progeny for the three transgenic lines. In common with previous data (Gluecksohn-Waelsch 1979; Russell et al. 1979|, no nontransgenic $c^{14 C o S}$ homozygotes $(0 / 35)$ were found to survive beyond the first day postnatum. In contrast, the great majority of $F a h$ transgenic $c^{14 C O S}$ homozygotes survived to weaning and beyond: $93 \%$ for line 1127 and $100 \%$ for line 1093. The death of some genotypically rescued individuals of line 1127 might not be significant, as a small number $(7 \%)$ of control albino offspring $\left(c / c^{14 C o S}\right)$ also died on the first postnatal day in these crosses. Viability was less complete in line 921 in which 15 of 21 transgenic $c^{14 \operatorname{CoS}}$ homozygotes $(71 \%)$ survived after birth (Table 1; Fig. 2). The lethalities might reflect the very low hepatic expression of the Fah transgene in line 921. There were no further fatalities of rescued mice of this line after postnatal day 1 . Rescued mice of all lines showed outwardly normal postnatal development and lifespan, although some line 921 rescued mice appeared to gain weight more slowly.

In separate $\mathrm{F}_{2}$ litters, albino offspring were sacrificed a few hours after birth for phenotypic analyses. Each was genotyped, and all analyses were performed on samples from individuals. Fah activity was determined in a limited number of livers (Fig. 3a), and found to be consistent with the prediction from the Northern blot analysis of the $\mathrm{F}_{1}$ mice. Rescued mice from line 1093 contained hepatic Fah activity greater than controls $190-220 \%$ of the wild-type mean); activities in livers of line 1127 rescued mice overlapped with the lower end of the wild-type range $(34-63 \%)$, and Fah was barely detectable in rescued mice of line $921(0.3-4.3 \%)$.

Blood was taken for glucose determination to test 
Figure 2. Identification of rescued $c^{14 C o s}$ homozygotes. $(a)$ Southern blot analysis of $\mathrm{F}_{2}$ albino progeny from the low Fah-expressing transgenic line 921, obtained from a cross between an $F_{1}$ male transgene carrier (genotype $c / c^{14 C o S}$ ) and two nontransgenic $c^{c h} / c^{14 C o s}$ females. EcoRI-digested tail DNA was hybridized with RN.Fd $(B g l)$. Rehybridizaton of the filter with JRN2.3 to confirm the identification of homozygotes for the $c^{14 C o S}$ deletion is shown in $b$. (Hybridization of JRN2.3 to the transgenes is not shown on this part of the autoradiograph.) (Lane 1) Homozygous $c$ (NMRI) DNA; (lane 2) homozygous $c^{14 C o s}$ DNA; (lanes 3-12) DNA from $\mathrm{F}_{2}$ albino progeny. Lanes 3 and 4 represent individuals that died $<1$ day after birth; the remaining lanes represent healthy mice genotyped at weaning. Lanes $8,10,12$ represent $c^{14 C o S}$ homozygotes "rescued" by the At:FAH transgene. The arrow marks the $1.3-\mathrm{kb}$ At:FAH transgene fragment. The probing strategy used to genotype mice is shown in $c$. The maps show $E c o$ RI restriction sites $(E)$ around the $5^{\prime}$ half of the Fah gene; exons are depicted as solid blocks. The $c^{14 C o S}$ deletion (lower line) removes exons I and II, as symbolized by the broken portion of the line, and creates a deletion-specific EcoRI fragment detected by genomic probe RN.Fd $|B g l|$. The probe includes exons IV and V and also detects EcoRI fragments diagnostic for the transgenes, $1.3 \mathrm{~kb}$ in the case of At:FAH, and $2.3 \mathrm{~kb}$ for Bg:FAH (see Fig. 1). Probe JRN2.3 contains exon I and maps within the region deleted in $c^{14 \operatorname{Cos}}$ so that it detects a 2.3-kb wild-type fragment and both transgenes.

whether the severe postnatal hypoglycemia of lethal albino mice (Erickson et al. 1968) was corrected in the transgenic rescued mice. Blood from control newborns contained between 8.5 and $90 \mathrm{mg} / \mathrm{dl}$ glucose, with most values falling in the $50-70 \mathrm{mg} / \mathrm{dl}$ range (Fig. $3 \mathrm{~b}$ ). In contrast, glucose was very low in most of the $c^{14 C o S}$ homozygotes, 12 of 14 having $<10 \mathrm{mg} / \mathrm{dl}$. Reconstitution experiments indicated that the assay could detect $\leqslant 10$ $\mathrm{mg} / \mathrm{dl}$, and mixing experiments gave no evidence that blood from the mutants contained substances interfering with the assay (data not shown). In blood from rescued individuals from lines 1093 and 1127, glucose was found within the wild-type range (Fig. 3b). In comparison, the values for individuals from line 921 appeared to divide between the normal and mutant distributions; 4 out of $10 \mathrm{had}<10 \mathrm{mg} / \mathrm{dl}$ glucose.

In conclusion, expression of transgenic Fah at levels similar to wild type corrects the hypoglycemia of $c^{14 \operatorname{Cos}}$ homozygotes and ensures normal survival. Very low neonatal expression of transgenic $\mathrm{Fah}$ is inadequate for glucose homeostasis in many individuals and is associated with some neonatal lethality.

Table 1. Survival of $\mathrm{c}^{14 \operatorname{Cos}}$ homozygotes inheriting Fah transgenes

\begin{tabular}{|c|c|c|c|c|c|c|}
\hline \multirow[b]{2}{*}{$\begin{array}{l}\text { Transgenic } \\
\text { line }\end{array}$} & \multirow[b]{2}{*}{ Progeny $^{a}$} & \multirow[b]{2}{*}{$\begin{array}{l}\text { Litters } \\
\text { examined }\end{array}$} & \multirow{2}{*}{$\begin{array}{l}\text { Number of } \\
\text { albino offspring } \\
\text { genotyped }^{\mathrm{b}}\end{array}$} & \multicolumn{3}{|c|}{$\begin{array}{l}\text { Survival of albino progeny } \\
\text { of the following genotypes }\end{array}$} \\
\hline & & & & $\begin{array}{c}c^{14 \operatorname{Cos}} / c^{14 \operatorname{CoS}} \\
-/-\end{array}$ & $\begin{array}{c}c^{14 C o S} / c^{14 C o S} \\
T g /-\end{array}$ & $\begin{array}{c}c / c^{14 C o S} \\
-/- \text { or } T g /-\end{array}$ \\
\hline 921 & $\mathrm{~F}_{2}$ & 7 & $28 / 30$ & $0 / 5$ & $5 / 7$ & $16 / 16$ \\
\hline 921 & $\mathrm{~F}_{3}$ & 12 & $26 / 30$ & $0 / 12$ & $10 / 14$ & N.A. ${ }^{d}$ \\
\hline 1127 & $\mathrm{~F}_{2}$ & 7 & $31 / 33$ & $0 / 4$ & $6 / 7$ & $18 / 20$ \\
\hline 1127 & $\mathrm{~F}_{3}$ & 3 & $14 / 14$ & $0 / 6$ & $8 / 8$ & N.A. ${ }^{d}$ \\
\hline 1093 & $F_{2}$ & 8 & $29 / 30$ & $0 / 8$ & $13 / 13$ & $7 / 8$ \\
\hline
\end{tabular}

${ }^{a} \mathrm{~F}_{2}$ progeny were obtained from crosses between $c / c^{14 C o S}$ carriers of the transgenes with nontransgenic $c^{c h} / c^{14 \operatorname{Cos}} ; \mathrm{F}_{3}$ progeny were from crosses between nontransgenic $c^{c h} / c^{14 C o S}$ and $c^{14 C o S} / c^{14 C o S}$ transgene carriers for line 1127 , and $c^{c h} / c^{14 C o S}$ transgene carriers for line 921.

${ }^{b}$ The fraction of the total albino offspring genotyped, with the remainder being fatalities whose carcasses were not later recovered. Pigmented and, therefore, control offspring were not always genotyped.

${ }^{c} \mathrm{Tg}$ indicates At:FAH transgene for line 921 and Bg:FAH transgene for lines 1127 and 1093.

d(N.A.) Genotype not applicable, as the $c$ allele is not present in these crosses. 


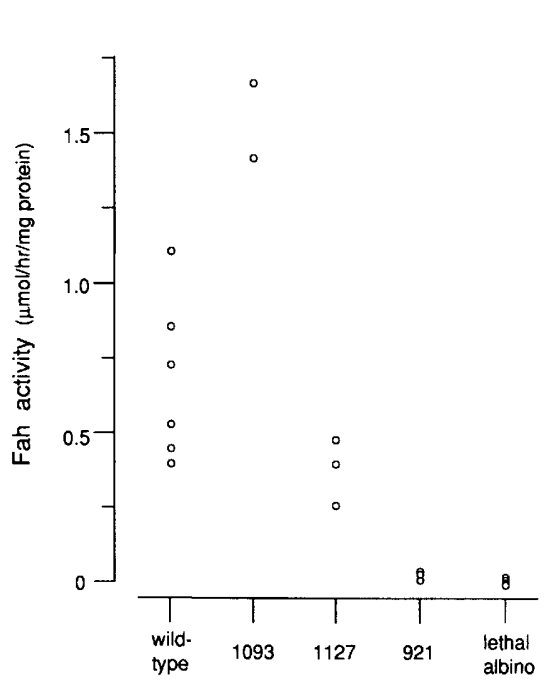

b

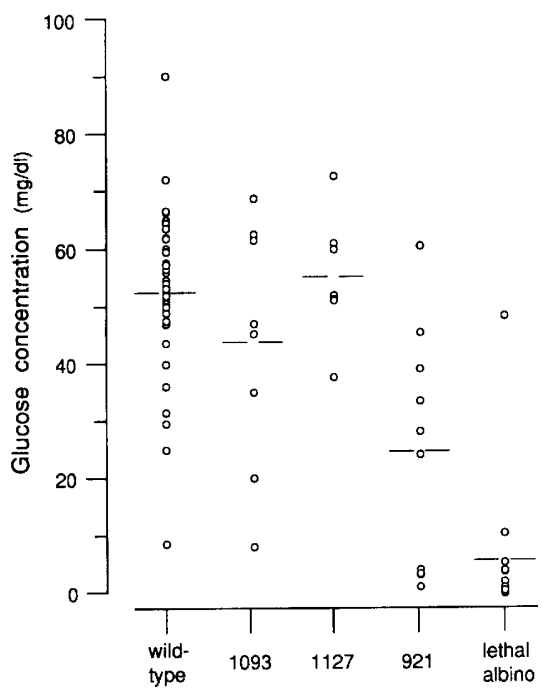

Figure 3. (a) Fah enzyme activity determination in livers of newborn $F_{2}$ albino progeny from transgenic lines 921,1093 , and 1127. Values from control offspring (genotype $\mathrm{c} / \mathrm{c}^{14 C o S}$ ) are collected in the column marked wild-type; nontransgenic $c^{14 C o S}$ homozygotes are in the lethal albino column. Values for $c^{14 \operatorname{CoS}}$ homozygotes carrying the three transgenic insertions and thus genotypically rescued are in the columns marked 1093, 1127, and 921 . (b) Glucose concentration was determined in blood of a larger set of newborn albino $\mathrm{F}_{2}$ progeny. Mean values marked as bars in each column are wild-type $=52.4 \mathrm{mg} / \mathrm{dl}$ [(population standard deviation) 13.8; $n=43$ ]; $1093=43.7 \mathrm{mg} / \mathrm{dl}$ (S.E.D. $21.0 ; n=$ 8); $1127=55.0 \mathrm{mg} /$ dl (S.E.D. $10.9 ; n=7$ ); $921=24.2 \mathrm{mg} / \mathrm{dl}$ (S.E.D. $20.9 ; n=10$ ); lethal albino $=5.7 \mathrm{mg} / \mathrm{dl}$ (S.E.D. $12.7 ; n=14$ ).
Correction of gene expression in liver of $\mathrm{c}^{14 \mathrm{Cos}}$ homozygotes expressing transgenic Fah

We wished to ascertain which of the many abnormalities in gene expression that characterize the $c^{14 \operatorname{Cos}}$ phenotype were corrected by expression of transgenic Fah. Initially, we examined newborn-rescued mice from line 1127 , as they showed complete restoration of neonatal blood glucose and good survival. A variety of mRNAs representing the spectrum whose expression is strongly altered in liver of $c^{14 C o S}$ homozygotes was analyzed. The mRNAs for tyrosine aminotransferase (TAT), phosphoenolpyruvate carboxykinase (PEPCK), glucose-6-phosphatase (G6Pase), serine dehydratase (Sdh), and S-adenosylmethionine transferase (Sams) belong to a class whose perinatal induction is abolished effectively; Hnf-4 and C/EBP $\alpha$ mRNAs encode liver-enriched transcription factors whose expression is significantly down-regulated; the mRNA for Nmo-1, an enzyme involved in oxidative detoxification, is strongly up-regulated; CHOP and fos mRNAs are induced in the mutant liver, possibly in response to DNA damage.

RNAs were prepared individually from livers of newborn albino $\mathrm{F}_{2}$ mice from five litters of line 1127. A total of 17 mice were analyzed, of which 7 were rescued, 5 were $c^{14 C o S}$ homozygotes, and 12 were controls. The Northern analysis of a representative litter is shown in Figure 4. Transgenic Fah mRNA was present in rescued mice at a level at least half of that of the endogenous Fah mRNA in control littermates $\left(c / c^{14 \operatorname{Cos}}\right)$, consistent with the Fah activity determinations in the same livers (Fig. 3a). There was some variation in the level of transgenic mRNA expression, in comparison with the consistent level of the endogenous Fah mRNA in control livers (Fig. 4; data not shown). This variability might result from an effect of the integration site together with the mixed genetic makeup of the $\mathrm{F}_{2}$ offspring.

Hybridization of duplicate Northern blots showed that rescued offspring expressed high levels of TAT and
PEPCK mRNAs, comparable with control littermates, in contrast to the very low levels in the lethal albino mice (Fig. 4). Wild-type levels of these mRNAs were found in all rescued livers, irrespective of the slight variation in the level of transgenic Fah mRNA. Comparable results were found for G6Pase, Sdh, and Sams mRNAs (data not shown). Similarly, the rescued mice were found to have restored to wild-type levels the expression of mRNAs for Hnf-4 and C/EBPa (Fig. 4).

Examination of two of the mRNAs highly induced in lethal albino liver, Nmo-1 and CHOP, revealed that their expression was restored to basal wild-type levels in all rescued offspring (Fig. 4). Correction of fos mRNA overexpression was more difficult to evaluate because of the variation among nontransgenic $c^{14 C o S}$ homozygous offspring, most but not all of which showed strongly elevated levels. In none of the rescued livers, however, did the level of fos mRNA approach that typically seen in $c^{14 C o S}$ homozygotes (data not shown). The variation in fos mRNA expression in nontransgenic $c^{14 C o s}$ homozygotes might reflect, in part, the mixed genetic background of these $F_{2}$ offspring.

These results establish that absence of Fah is the primary defect underlying the $c^{14 C o S}$ neonatal lethal phenotype and that all effects on gene expression arise secondarily to this metabolic deficiency. In particular, the high neonatal levels of TAT and PEPCK mRNAs in rescued mice imply that hormone-regulated gene expression is fully restored.

Partial rescue of the $\mathrm{c}^{14 \operatorname{Cos}}$ phenotype in the presence of low levels of transgenic Fah

Rescued $c^{14 C o S}$ homozygotes from transgenic line 921 expressed little detectable Fah activity $(0.3-4.3 \%)$ and mRNA $(\sim 2 \%)$ in liver at birth. Nevertheless, many individuals had normal postnatal blood glucose concentrations and most survived with a normal lifespan. We 


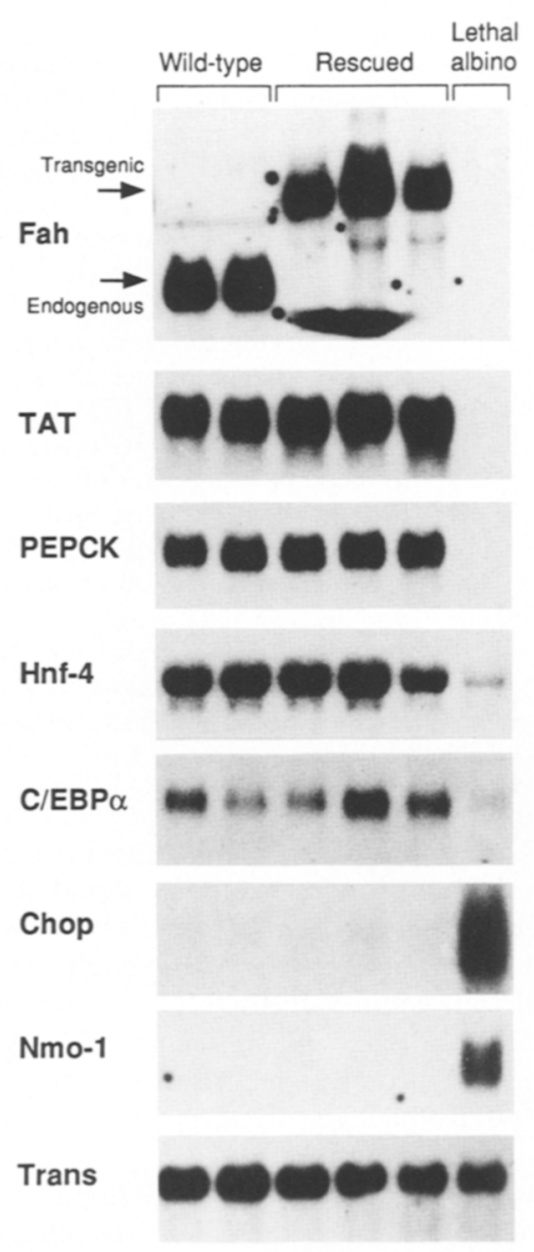

Figure 4. Northern blot analysis of liver of newborn albino $F_{2}$ mice from transgenic line 1127 shows complete correction of the lethal albino phenotype in rescued mice. The Northern blots contain total RNAs $(5 \mu \mathrm{g})$ from six offspring from a single litter taken 4-8 hr after birth. Lanes are labeled as follows: (Wild-type) $c / c^{14 C o S}$ controls; (Rescued) $c^{14 C o S}$ homozygotes carrying the $\mathrm{Bg}: \mathrm{FAH}$ transgene; (Lethal albino) the nontransgenic $c^{14 C o S}$ homozygotes. The same or duplicate filters were hybridized with the antisense riboprobes for the cDNAs indicated. Signals corresponding to the endogenous and transgenic derived Fah mRNAs are identified by labeled arrows. Hybridization to a transferrin (Trans) cDNA probe is shown as a loading control.

wanted to establish the levels of Fah expression sufficient for postnatal survival and to investigate the extent to which a normal pattern of gene expression was maintained. This might reveal whether aspects of the complex lethal albino phenotype can be separated.

$\mathrm{F}_{2}$ and $\mathrm{F}_{3}$ offspring were sacrificed on various days after birth. RNA was prepared from individual livers, and Fah activity and immunoreactive material (IRM) determined. Transgenic Fah mRNA and IRM was detected in all genotypically rescued mice (Northern blot analysis is shown in Fig. 5), but at low or very low levels in comparison with the endogenous species in control littermates, and with considerable variation between mice of a given age. On days 1 and 2, Fah IRM did not exceed $4 \%$ of the mean of age-matched controls, with most individuals having $<2 \%$. Although Fah mRNA and IRM levels increased in the immediate postnatal period, some rescued mice on day $22 \mathrm{had}<5 \%$ of the control levels.

The consequences of such low levels of Fah on the expression of other mRNAs in the liver was examined. TAT mRNA accumulated to wild-type levels in 8 of 10 rescued mice at day 1 (Fig. 5; data not shown). Although there was a deficit of TAT mRNA in many rescued livers on day 2, rescued mice expressed wild-type levels at later stages. PEPCK and G6Pase mRNAs behaved in a similar manner to TAT mRNA, and wild-type levels of Sams mRNA were detected in most rescued livers on day 1 (data not shown).

Although CHOP mRNA remained significantly or strongly induced in livers of many younger rescued mice ( 7 of 10 on day $1 ; 2$ of 5 on day 2), there was no apparent overexpression at later ages (Fig. 5; data not shown). The pattern of fos mRNA expression was similar, although individual mice could be discordant for high levels of these two mRNAs. The overexpression of $\mathrm{CHOP}$ and fos mRNAs on days 1 and 2 correlated to some extent with lower levels of transgenic Fah mRNA. In addition, high levels of CHOP or fos mRNAs were often, but not always, accompanied by reduced levels of TAT and PEPCK mRNAs. Nmo-1 mRNA, in contrast, remained strongly elevated in rescued livers of all ages, although the degree of overexpression had declined slightly in older livers. The persistent elevation of Nmo-1 mRNA implies that the level of Fah activity provided by the transgene in rescued mice of line 921 is not sufficient entirely to prevent accumulation of harmful metabolites of tyrosine metabolism.

In conclusion, the extent to which a normal pattern of gene expression is restored in liver depends, at least in part, on the level of transgenic Fah. The different behavior of the mRNAs examined suggests that the misregulation of each is sensitive to different levels of tyrosine metabolites or to different types of intracellular insult that they cause.

\section{Rescue of gene expression in kidney of $\mathrm{c}^{14 \mathrm{Cos}}$ homozygotes}

A pattern of abnormalities in gene expression similar to that described in the liver occurs in the proximal convoluted tubules of the kidney in $c^{14 \operatorname{Cos}}$ homozygotes, although the magnitude of the effect on hormone-inducible mRNAs may not be as great (Ruppert et al. 1990). Because the level of transgenic Fah expression in newborn liver and kidney differed greatly between the three transgenic lines, it was of interest to examine whether the kidney phenotype was corrected, as this might help to indicate to what extent the phenotype arises intrinsically to the kidney.

RNA was prepared from kidneys of the same newborn $\mathrm{F}_{2}$ offspring examined for blood glucose and gene expression in liver. Mice from transgenic line 1127 express transgenic Fah mRNA at levels close to wild type in the 


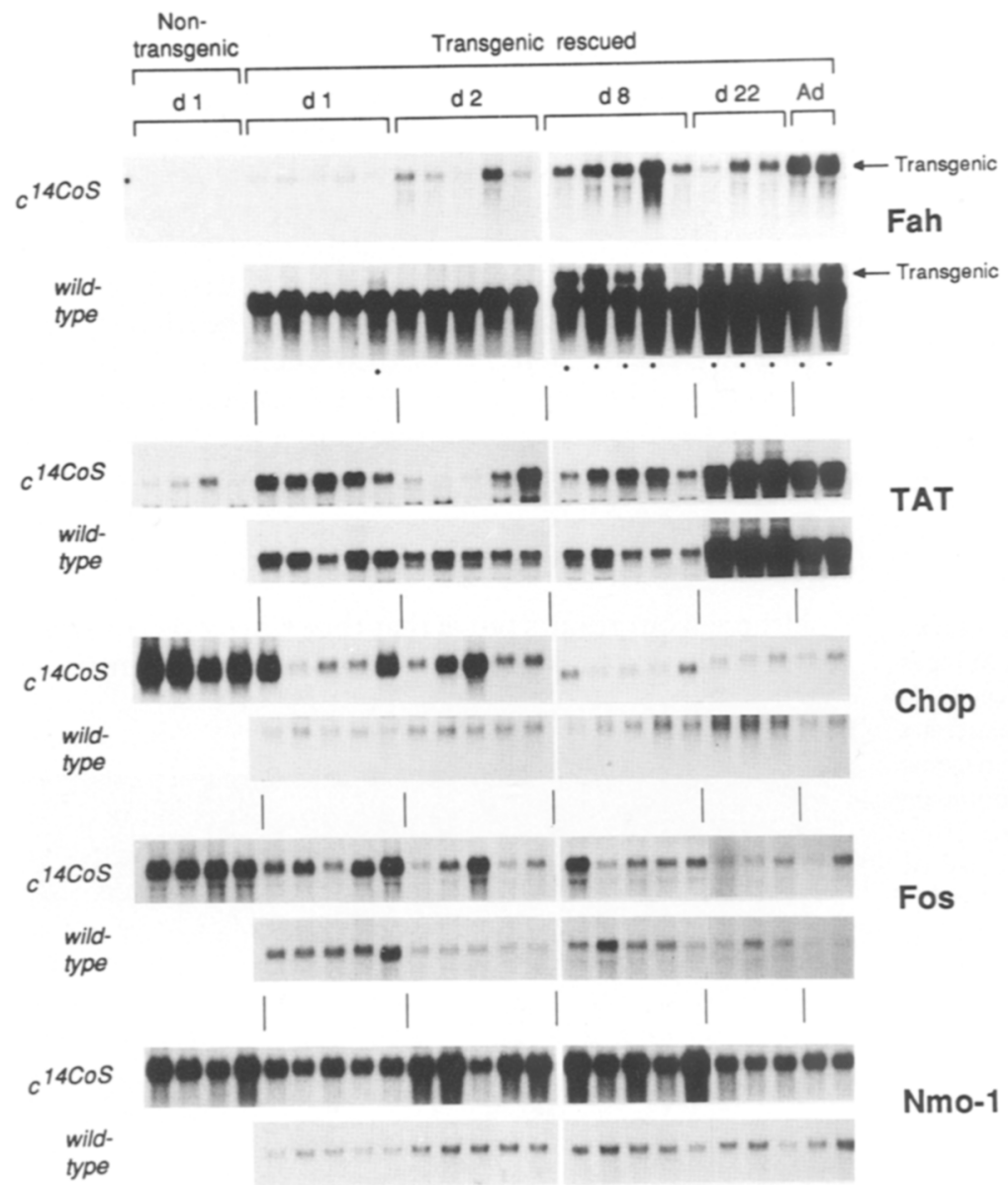

Figure 5. Northern blot analysis of RNA from livers of rescued mice from low-expressing transgenic line 921. Total RNAs (5 $\mu \mathrm{g}$ per lane) are from $F_{2}$ progeny on day 1 postnatum $(d 1), F_{3}$ progeny for postnatal days 2,8 , and 22 , and adult (Ad) $F_{2}$ mice. RNAs from nontransgenic (d1) and transgenic rescued ( $\mathrm{dl}-\mathrm{Ad}) \mathrm{c}^{14 \cos }$ homozygotes are shown in the top panel for each probe; the bottom panel, marked wild-type, contains RNAs from conrtol offspring of the corresponding ages. Control individuals transgenic for At:FAH are identified by asterisks. Transgenic Fah mRNAs are indicated by the labeled arrows. For each probe the autoradiographs shown come from the same hybridization and received the same exposure. Loading was controlled by hybridization with a probe for transferrin, which indicated that there were no significant quantitative and qualitiative differences between samples (not shown). kidney. In line 1127 rescued mice, expression of PEPCK, G6Pase, and Nmo-1 mRNAs (Fig. 6; data not shown) returned to normal. Surprisingly, a similarly corrected phenotype was seen in rescued mice from transgenic line 1093, in which, despite high level expression of the transgene in liver, no transgenic Fah mRNA was detected in newborn kidney. Although we cannot rule out the possibility that sufficient transgenic Fah is expressed in the specific cells in the kidney, beyond our detection ability, this result suggests that a phenotype is unlikely to develop in kidney if rescue is complete in the liver.

Newborn rescued mice from line 921, in which little or no Fah mRNA is present in both kidney and liver, presented a more complex phenotype. Overexpression of Nmo-1 mRNA was found in two of four, whereas normal expression of G6Pase mRNA was found in three and PEPCK mRNA in all four rescued individuals (Fig. 6; data not shown). This less than complete phenotypic correction in kidney suggests that the partial rescue in the liver in this line is not sufficient to protect the kidney from the consequences of the Fah deficiency. Thus, if induction of tyrosine metabolism in the kidney is a response to neonatal hypoglycemia, or some other altered physiological parameter, deficiency of Fah may be exposed and tyrosine metabolites accumulate.

\section{Correction of ultrastructural abnormalities in rescued $\mathrm{c}^{14 \mathrm{Cos}}$ homozygotes}

An altered hepatocyte ultrastructure has been described as part of the $c^{14 C o S}$ phenotype (Trigg and GluecksohnWaelsch 1973). We therefore wanted to determine whether this abnormality was also corrected by expression of transgenic Fah. Livers from albino $\mathrm{F}_{3}$ offspring from lines 1127 and 921 were examined by transmission electron microscopy. In agreement with the previous findings, hepatocytes from the livers of nontransgenic $c^{14 \operatorname{CoS}}$ homozygotes showed extensive ultrastructural changes. The altered organization of the ER was most prominent and was manifested as extensive infiltrations of the cytoplasm by loosely parallel membranes, sometimes assuming concentric arrangements, and large vesicles (Fig. 7c,d). Hepatocytes with a normal appearance were seldom encountered. The preparation from the rescued individual from line 1127 presented an entirely normal ultrastructure (data not shown), in keeping with the complete correction of other aspects of the phenotype in this high Fah-expressing line. Livers from rescued mice from the low-expressing line 921 showed an almost normal ultrastructure (Fig. 7e,f). The ER generally assumed the compact parallel organization typical of wild-type 


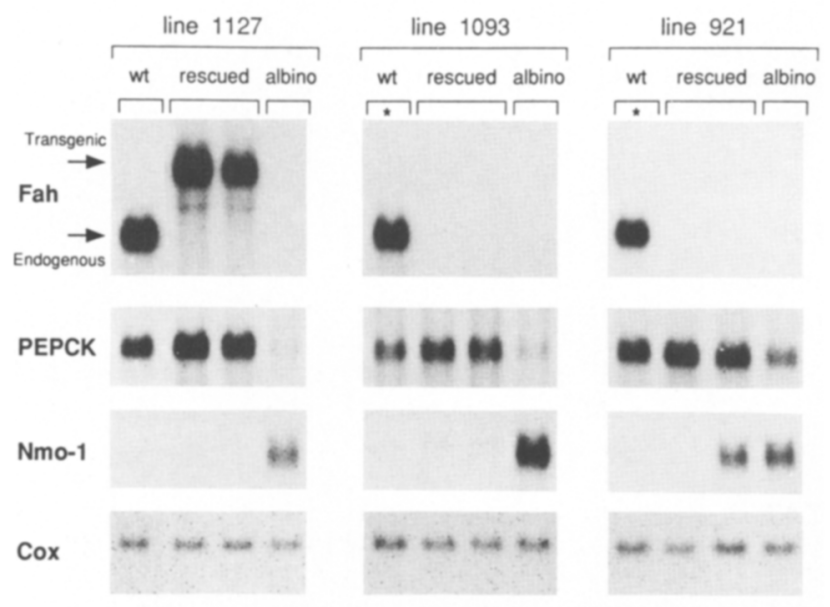

Figure 6. Northern blot analysis of kidney RNA from rescued mice. Northern blots containing total RNAs (4 $\mu \mathrm{g})$ from kidneys from individual newborn $\mathrm{F}_{2}$ albino progeny of the three transgenic lines were hybridized with the probes indicated. Lanes are labeled as follows: (wt) Control offspring, (rescued) transgenic $c^{14 \operatorname{CoS}}$ homozygotes; (albino) nontransgenic $c^{14 \operatorname{Cos}}$ homozygotes. The samples from each transgenic line are from littermates. Control mice carrying the transgenes are identified by asterisks. The positions of the endogenous and transgenic Fah mRNAs are indicated by labeled arrows. Equivalence of loading was checked by hybridization to a cDNA probe for subunit 1 of the mitochondrial cytochrome oxidase (Cox).

hepatocytes (Fig. 7, cf. b with f). Some areas of less wellorganized ER reminiscent of the lethal albino phenotype were seen, but gross abnormalities on the scale of the mutant hepatocytes were not present.

\section{Discussion}

Fah deficiency is the cause of the lethal albino phenotype

Interest in the neonatal lethal albino phenotype arose from the failure in induction of hormone-dependent genes in the newborn liver, on the basis of which the existence of a regulatory locus, alf or $h s d r-1$, on mouse chromosome 7 was proposed (Gluecksohn-Waelsch 1979; Ruppert et al. 1990). The finding by positional cloning that the lethal albino deletion $c^{14 C o s}$ disrupts the gene for Fah (Klebig et al. 1992; Ruppert et al. 1992) suggested an alternative origin for this phenotype. We proposed that the failure to metabolize electrophilic intermediates of tyrosine breakdown would induce a stress state within the cell, such as oxidative stress, that would ultimately lead to misregulation of gene expression (Ruppert et al. 1992; Kelsey and Schütz 1993). We have tested this hypothesis by complementing the $c^{14 \operatorname{Cos}}$ deletion with $\mathrm{Fah}$ transgenes. Providing transgenic $\mathrm{c}^{14 \mathrm{Cos}}$ homozygotes express Fah in the liver at a level $\geqslant 30 \%$ of that of wild-type mice, complete phenotypic correction is achieved. This included the expression of markers for the various abnormalities in gene expression, neonatal blood glucose homeostasis, hepatocyte ultrastructure, and viability. Furthermore, whether complementation was complete or partial depended on the dose of Fah transgene expression. These results establish $\mathrm{Fah}$ as the gene mapping at alf/hsdr-1. In addition, they show that the phenotype on which the putative negative trans-regulatory locus Nmo-1n was inferred (Petersen et al. 1989) is another consequence of Fah deficiency. Finally, as the transgenic rescued mice are viable and fertile, and display no obvious phenotype apart from the albinism resulting from the deletion of the $c$ locus, it can be concluded that there are no other genes essential for survival within the $3.8-\mathrm{Mb}$ region spanned by the $c^{14 \mathrm{CoS}}$ deletion (Kelsey et al. 1992).

\section{Tyrosine metabolites and effects on gene expression}

Although our results prove that the primary defect is not within a regulatory gene, the pattern of gene expression

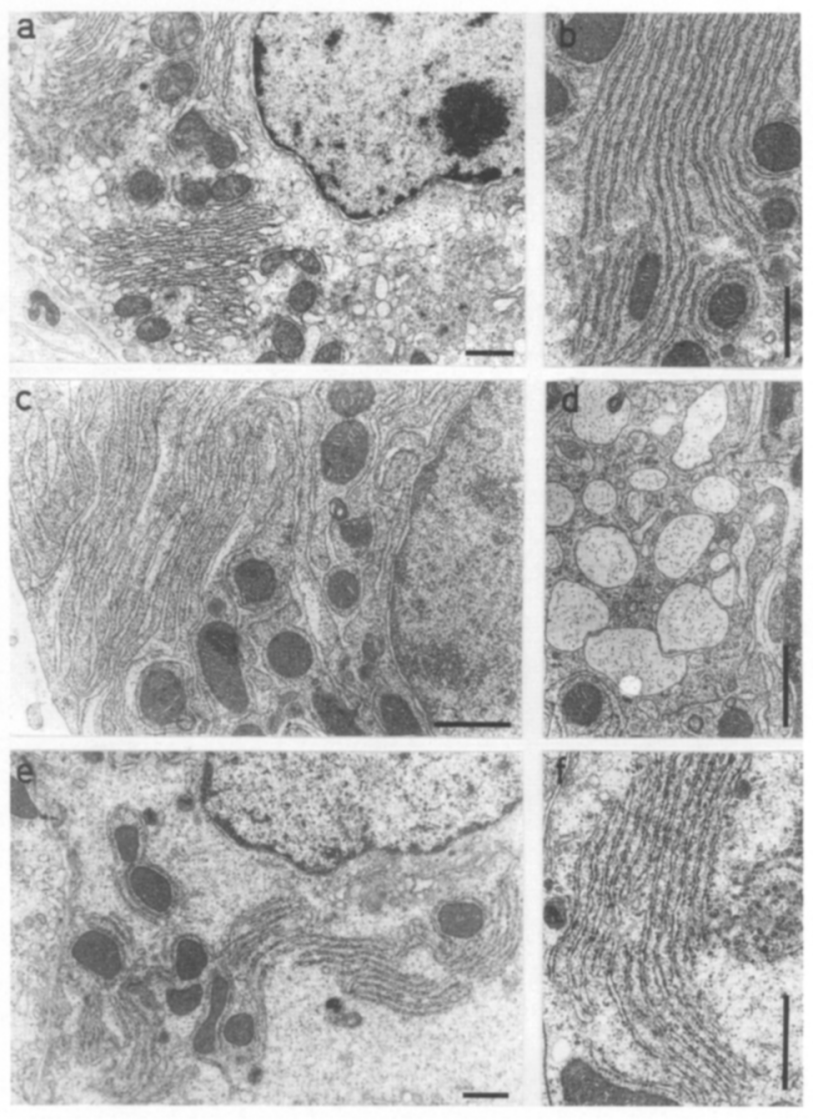

Figure 7. Transmission electron micrographs of ultrathin sections from livers of newborn mice of transgenic line 921 . Sections from a control liver showing characteristic hepatocyte ultrastructure $(a)$ and closely packed parallel arrays of rough ER (b). Hepatocytes from nontransgenic $c^{14 C o S}$ homozygotes typically show extensive infiltration of the cytoplasm by what seems to be smooth ER (c) that, in a different plane of section, appears as numerous large vesicles $(d)$. Hepatocyte ultrastructure of transgenic rescued $c^{14 C o S}$ homozygotes $(e, f)$ shows a granular cytoplasm and rough ER organization similar to wild type. Bars, $1 \mu \mathrm{m}$. 
in the neonatal liver is profoundy altered and deserves to be addressed. By examining $c^{14 C o S}$ homozygotes complemented by markedly different levels of transgenic Fah, it becomes clear that the various effects on gene expression, although resulting ultimately from Fah deficiency, can have independent causes. The links between tyrosine metabolites and gene expression remain obscure, however, and are likely to be more complex than envisaged previously (Kelsey and Schütz 1993). The persistent overexpression of Nmo-1 mRNA, the only residual phenotype in rescued mice from the low Fah-expressing line 921 , is consistent with our earlier conclusion that induction of the Nmo-1 gene is the most immediate and sensitive of the responses to tyrosine metabolites (Ruppert et al. 1992). Overexpression of CHOP and fos mRNAs is ultimately corrected even in line 921 rescued mice. Therefore, the induction of their genes may only occur in response to higher levels of the reactive metabolites or, more likely, secondarily to intracellular "damage". Because high levels of fos and CHOP transcripts were not fully concordant in lethal albino and rescued mice of line 921, these genes may be reacting to different types of stress or damage. Induction of the CHOP gene (gadd153) in response to DNA damage, for example, is apparently independent of fos expression (Bartlett et al. 1992).

The perinatal activation of genes, such as TAT and PEPCK, which are subject to tissue-specific and hormonal regulation, is likely to be a complex process sensitive to interference at many levels. Activation of the rat TAT gene is brought about by the synergistic effects of glucocorticoids and cAMP (Ruiz-Bravo and Ernest 1982) operating by two liver-specific enhancers (Jantzen et al. 1987; Boshart et al. 1990). Both enhancers depend on interactions between constitutive liver-specific and hormone-responsive elements (Nitsch et al. 1993). Modest decreases in the concentration or activity of factors essential for activity of these elements could be sufficient to prevent a strong activation of transcription. Certainly, the expression of genes for several liver-enriched transcription factors is down-regulated in the lethal albino liver (e.g., Tönjes et al. 1992). The fact that the appearance of DNase I hypersensitive sites upstream of the TAT gene is not grossly altered in the lethal albino liver might imply, however, that the complement of enhancer-binding factors is not substantially altered (Zaret et al. 1992).

The potential for interference in gene induction is suggested by the strong overexpression of CHOP and fos: CHOP could inhibit C/EBP-like proteins /Ron and Habener 1992), and one effect of fos could be to antagonize glucocorticoid receptor function (Jonat et al. 1990; Yang-Yen et al. 1990). Although in the case of CHOP the correlation is good, the presence of elevated CHOP mRNA was not accompanied by a deficit of TAT or PEPCK mRNAs in all rescued mice from line 921. Moreover, in nuclear extracts from homozygous $c^{14 C o s}$ liver, we have not been able to demonstrate a significant reduction in C/EBP-binding activity despite the presence of high levels of CHOP protein (G. Kelsey and D. Ron, unpubl.). Overexpression of $\mathrm{CHOP}$ in transgenic mice or in cell culture models may be required to establish its role, if any, in the phenotype. Likewise, a role of fos overexpression cannot simply be assumed, particularly because it was not a fully penetrant phenotype. High levels of fos mRNA in newborn livers were generally associated with a negative effect on TAT and PEPCK mRNAs, but not all $c^{14 C o S}$ homozygotes overexpressed fos mRNA and high levels were seen in a few wild-type individuals. Set against this inconsistency, induction of fos in transgenic mice leads to inhibition of glucocorticoid and cAMP induction of TAT mRNA /U. Rüther, pers. comm.), and similar effects on TAT mRNA accompany fos induction in rat hepatoma cells in response to phorbol ester treatment (A. Reik and G. Schütz, unpubl.). The availability of mice carrying null alleles of c-fos (Johnson et al. 1992; Wang et al. 1992) will help to define more clearly the involvement of fos in the phenotype.

In the lethal albino kidney Nmo-1 and CHOP mRNAs are induced specifically in the cell type that should normally express Fah (Ruppert et al. 1992; G. Kelsey, E. Schmid, and D. Ron, unpubl.), which implies that tyrosine metabolites are very short-range reactants acting only within the cells in which they accumulate. In the human deficiency state it has been suggested that renal tubular dysfunction is brought about by circulating tyrosine metabolites (Goldsmith and Laberge 1989). We should like to interpret our results on the pattern of gene expression in the three transgenic mouse lines to suggest that the kidney phenotype, although caused by tyrosine metabolites produced in the kidney, is influenced by extrinsic factors. A phenotype is more likely to arise when the liver is not fully competent to maintain blood glucose, or some other physiological parameter, so that renal tyrosine metabolism is activated as part of the gluconeogenic response.

\section{Fah deficiency in humans and mice}

The demonstration that the lethal albino phenotype results from Fah deficiency establishes lethal albino mice as a potential animal model for the human inborn error of metabolism HT1. HT1 is a liver disease of varying severity and clinical outlook (Kvittingen 1986; Goldsmith and Laberge 1989). The severity may be related to the degree of Fah deficiency, the molecular basis of which is heterogeneous (Tanguay et al. 1990; Phaneuf et al. 1992). The mouse and human phenotypes differ strikingly, however, in that lethal albino mice die within hours after birth, whereas absolute Fah deficiency in humans is tolerated for many months, albeit with severe liver failure. It is possible that this discrepancy reflects differences in tyrosine metabolism between the two species. In this respect, it is interesting that a by-product of tyrosine catabolism, succinylacetone, whose appearance in high concentration in extracellular fluids is diagnostic for HT1 (Kvittingen 1986; Goldsmith and Laberge 1989), is detected only in trace amounts, if at all, in lethal albino liver (Collins et al. 1992), blood, and urine (G. Kelsey, R.M. Tanguay, and A. Grenier, unpubl.). Alternatively, adequate mechanisms to detoxify tyrosine me- 
tabolites may not be present in the fetal mouse liver, with the result that a metabolic crisis arises, (e.g., oxidative stress), which leads to a profound disturbance of gene regulation. This crisis occurs at a time when the liver is undergoing significant changes in the pattern of gene expression to meet the new physiological status at birth, changes that might be acutely sensitive to misregulation. The condition is likely to be exacerbated by enhanced tyrosine degradation in response to neonatal hypoglycemia. The longer gestation in humans might allow sufficient protective mechanisms to develop that forestall a similar neonatal crisis. Differences between humans and rodents in the ontogeny of detoxification enzymes are known (Leakey 1983). There is no indication of consistent abnormalities in gene expression in HTl livers comparable with the lethal albino phenotype (Y. Labelle, D. Phaneuf, and R.M. Tanguay, unpubl.).

The usefulness of lethal albino mice as a model of HTl is limited by their early death: A partial deficiency of Fah with enhanced survival would be advantageous. Considering the strong phenotype caused by total absence of Fah, it is surprising how mild a phenotype is associated with the very low levels of Fah in rescued mice of line 921. Less than $4 \%$ of wild-type levels of Fah enable the majority of genotypically rescued mice to survive the critical newborn period and are sufficient for viability and the restoration of a near normal pattern of gene expression. In humans, deficiency of Fah to $\sim 30 \%$ of normal leads to a chronic liver disease with multiple histological changes and a high predisposition to childhood hepatoma (Dehner et al. 1989; Russo and O'Regan 1990; Tanguay et al. 1990; Phaneuf et al. 1992). In the limited histological analyses carried out to date, rescued mice of line 921 show no consistent liver pathology (G. Kelsey, unpubl.). More extensive follow-up studies will be required to establish whether neoplastic changes occur. It is possible that Fah is normally expressed at levels well in excess of the normal flux through the tyrosine degradation pathway, so that enzyme activity is sufficient even in these low expressing mice. The persistent Nmo-1 mRNA overexpression indicates, however, that enzyme activity is not sufficient to prevent some accumulation of tyrosine metabolites. It might be possible to expose the partial deficiency of Fah to precipitate a more severe phenotype by metabolic interventions, such as loading with tyrosine intermediates such as homogentisic acid (Laberge et al. 1990; Ruppert et al. 1992).

The abnormal hepatocyte ultrastructure of lethal albino mice was corrected by transgenic Fah expression, identifying this aspect of the phenotype as another consequence of Fah deficiency. Substantial alterations in ultrastructure can be elicited in liver parenchymal cells by metabolic disturbances or drugs (Miyai 1979), often accompanied by induction of detoxifying systems. HT1 livers show a diverse spectrum of ultrastructural alterations, none of which are viewed as being specific to the disease (Dehner et al. 1989; Russo and O'Regan 1990). A comparison with the lethal albino condition is complicated by the duration of the insult in HTl livers and various cirrhotic changes that have taken place. How- ever, one study has stressed specific features in young patients, some of which might resemble the abnormalities in lethal albino mice (Tremblay et al. 1977).

In conclusion, our results unequivocally establish that the deficiency of an enzyme, Fah, is the basis of the lethal albino phenotype. This finding suggests that an accumulation of toxic intermediates of tyrosine metabolism, or by-products thereof, is likely to be responsible for a variety of intracellular damage and responses that lead to multiple alterations at the level of gene expression.

\section{Materials and methods}

Transgenic constructs

Transgenic constructs Bg:FAH and At:FAH were derived from the near full-length mouse Fah cDNA clone pmcFAH7 (Ruppert et al. 1992). The 3'-most 60 nucleotides of the cDNA, including the polyadenylation signal and poly $(\mathrm{A})$ tract, were removed by exonuclease III digestion and replaced by the SV40 small intron and 3'-processing region from pHD (Müller et al. 1988). $\mathrm{Bg}$ : $\mathrm{FAH}$ contains a 4.7-kb BglII fragment from the mouse Fah gene extending from $1.2 \mathrm{~kb} 5^{\prime}$ to the transcriptional start site to the Bglll site within exon 2 at position 113 (numbered from the $A$ of the initiating codon), fused to cDNA sequences downstream of the BgIII site. At:FAH contains the upstream region of the human $\alpha$-1-antitrypsin gene from an $X \mathrm{cmI}$ site at position 31 to a BamHI site at $-3.7 \mathrm{~kb}$, isolated from plasmid ATp4 (Kelsey et al. 1988), fused to the Fah cDNA at position -48 . The sequences of the entire coding regions of both constructs were verified with internal sequencing primers (Ruppert et al. 1992). Further details of cloning manipulations are available on request.

\section{Transgenic mice}

Gel-purified DNA was microinjected into oocytes from superovulated NMRI/Han mice, and transgenic mice were generated as described previously (Hogan et al. 1986; Beermann et al. 1990). Transgenic founders were identified by Southern blot analysis of DNA from tail biopsies, in which EcoRI-digested DNAs were hybridized to a ${ }^{32} \mathrm{P}$-labeled riboprobe corresponding to sequences $3^{\prime}$ to the BgIII site in cDNA clone pmcFAH3 (Ruppert et al. 1992). Because this probe does not hybridize to the EcoRI fragment containing exon 1 of the Fah gene, the Bg:FAH transgene is detected as a $2.3-\mathrm{kb}$ and the At:FAH transgene as a $1.3-\mathrm{kb} E c o$ RI fragment. From the microinjections with construct Bg:FAH, 17 of 82 mice born were transgenic, of which 9 were bred for further analysis. Four transgenic founders were obtained from 36 live born mice for At:FAH.

The $c^{14 \operatorname{CoS}}$ lethal albino deletion is maintained opposite the chinchilla $(\mathrm{ch})$ allele at the $c$ locus, which determines a diluted pigmentation. NMRI transgenic founders were crossed with $c^{c h} / c^{14 C o s}$ mice to obtain $\mathrm{F}_{1}$ transgenic albino $\left(c / c^{14 C o s}\right)$ and pigmented $\left(c / c^{c h}\right)$ offspring. Livers and kidneys were taken from the pigmented $F_{1}$ mice for RNA analysis. Transgenic albino $F_{1}$ mice from selected lines were backcrossed with $c^{c h} / c^{14 \operatorname{CoS}}$ to obtain transgenic and nontransgenic $c^{14 C o s}$ homozygotes among the $F_{2}$ albino progeny. Albino $F_{2}$ mice were sacrificed a few hours after birth by decapitation, and livers, kidneys, and whole blood were frozen separately in liquid nitrogen and stored at $-70^{\circ} \mathrm{C}$. Livers were generally divided into two, one for the preparation of RNA and one for Fah protein determination. Tail and hindlimbs were collected for genotyping. Separate $F_{2}$ litters 
were left undisturbed, the carcasses of fatalities were collected, and tail biopsies were taken from survivors at weaning for genotyping. $F_{3}$ offspring were obtained by mating $F_{2}$ carriers of the transgenes (genotype $c^{14 \operatorname{CoS}} / c^{14 \operatorname{CoS}}$ or $c^{c h} / c^{14 C o S}$ ) with nontransgenic $c^{\text {ch }} / c^{14 C o s}$ mice.

Mice were genotyped by Southern blot analysis with a singlecopy riboprobe made from template RN.Fd(Bgl) (Ruppert et al. 1992). The identity of $c^{14 C o S}$ homozygotes was verified, in some cases, by hybridization with probe JRN2.3 (Ruppert et al. 1992) or a tyrosinase cDNA, pmcTyr102 (Ruppert et al. 1988).

\section{Blood glucose determination}

Whole blood frozen from newborns was thawed, 10- $\mu$ l samples were deproteinized with zinc sulfate and barium hydroxide, and glucose levels were determined by the glucose oxidase method using a scaled-down version of a diagnostic kit (Sigma 510-DA). Owing to the small volumes of blood obtained, duplicate determinations could not be performed routinely. The duplicate assays that were done showed little variation.

\section{Fah determination}

Fah activity in liver homogenates was measured using fumarylacetoacetate as a substrate. For immunoblots, duplicates of liver homogenates $(20-40 \mu \mathrm{g})$ were electrophoresed, transferred, and immunoblotted with an affinity-purified rabbit anti-rat Fah antibody and a secondary ${ }^{125} \mathrm{I}$-labeled goat anti-rabbit immunoglobulin G. Fah was quantified by scanning the autoradiographs and counting the radioactivity in the immunoreactive band (Tanguay et al. 1990; Phaneuf et al. 1992).

\section{RNA analysis}

RNA was prepared by a simplified and scaled down version of the urea/LiCl method (Auffrey and Rougeon 1980). Preparation of Northern blots and hybridizations with ${ }^{32} \mathrm{P}$-labeled antisense riboprobes were performed as described previously (Ruppert et al. 1990). Loading and RNA quality was checked by UV shadowing of filters and by hybridization of control probes: transferrin and albumin in the case of liver RNAs, Cox for kidney. Crude quantification of transgenic Fah mRNA was made by comparison with Fah mRNA in loading controls of wild-type RNA. cDNA probes for Fah, C/EBP $\alpha$, fos, Nmo-1, PEPCK, TAT, transferrin, Sams, and Sdh have been described (Ruppert et al. 1990,1992). cDNA X1 (Ruppert et al. 1990) has been identified recently to encode G6Pase (Shelly et al. 1993). The probe for CHOP corresponds to nucleotides 90-590 of the cDNA (Ron and Habener 1992). The Hnf-4 probe was made from a $1.2 \mathrm{~kb}$ $P v u I I$ fragment cloned into Bluescript KS (Stratagene) that contains coding and 3 '-untranslated sequences of the rat Hnf-4 cDNA (Sladek et al. 1990; G. Kelsey and S. Taraviras, unpubl.). Plasmid for preparation of the Cox probe (Murphy et al. 1983) was obtained from C. Birchmeier (Max-Delbrück-Laboratorium, Cologne, Germany).

\section{Electron microscopy}

Small parts of livers from newborn $\mathrm{F}_{3}$ offspring of lines 1127 and 921 were fixed either in $2.5 \%$ glutaraldehyde or $2.5 \%$ glutaraldehyde plus $2 \%$ osmium tetroxide, in either case, in a buffer containing $50 \mathrm{~mm}$ sodium cacodylate $(\mathrm{pH} 7.2\}, 50 \mathrm{mM} \mathrm{KCl}$, and $2.5 \mathrm{~mm} \mathrm{MgCl}$, at $4^{\circ} \mathrm{C}$ for $30 \mathrm{~min}$. Washing, postfixation in osmium tetroxide ( $2 \%$ in the same buffer), dehydration, embedding, and ultrathin sectioning were done as described previously (Franke et al. 1976).

\section{Acknowledgments}

We are grateful to E. Thies and F. Lettre for technical assistance, and W. Fleischer and J. Hecker for photography. D. Ron, C. Birchmeier, and J. Darnell Jr. kindly provided probes. We thank A. Schedl and D. Ron for their continued interest and helpful discussions, S. Gluecksohn-Waelsch for stimulating our interest in lethal albino mice, W. Franke for help in interpreting electron micrographs, and A.P. Monaghan and M. Boshart for comments on this manuscript. This work was supported by the Deutsche Forschungsgemeinschaft through SFB 229 and the Leibniz Programm, and the Fonds der Chemischen Industrie, and the Medical Research Council of Canada.

The publication costs of this article were defrayed in part by payment of page charges. This article must therefore be hereby marked "advertisement" in accordance with 18 USC section 1734 solely to indicate this fact.

\section{References}

Auffray, C. and F. Rougeon. 1980. Purification of mouse immunogluobulin heavy-chain messenger RNAs from total myeloma tumor RNA. Eur. J. Biochem. 107: 303-314.

Bartlett, J.D., J.D. Luethy, S.G. Carlson, S.J. Sollott, and N.J. Holbrook. 1992. Calcium ionophore A23187 induces expression of growth arrest and DNA damage inducible CCAAT/ Enhancer-binding protein $(\mathrm{C} / \mathrm{EBP}\}$-related gene, gadd153. $J$. Biol. Chem. 267: 20465-20470.

Beermann, F., S. Ruppert, E. Hummler, F.X. Bosch, G. Müller, U. Rüther, and G. Schütz. 1990. Rescue of the albino phenotype by introduction of a functional tyrosinase gene into mice. EMBO I. 9: 2819-2826.

Boshart, M., F. Weih, A. Schmidt, R.E.K. Fournier, and G. Schütz. 1990. A cyclic AMP responsive element mediates repression of tyrosine aminotransferase gene transcription by the tissue-specific extinguisher locus Tse-1. Cell 61: 905916.

Collins, J.C., D.N. Buchanan, J.G. Thoene, R.P. Erickson, S.S. Brooks, and S. Gluecksohn-Waelsch. 1992. Metabolic studies in a mouse model of hepatorenal tyrosinemia: Absence of perinatal abnormalities. Biochem. Biophys. Res. Commun. 187: 340-346.

DeFranco, D., S.M. Morris, C.M. Leonard, and S. GluecksohnWaelsch. 1988. Metallothionein mRNA expression in mice homozygous for chromosomal deletions around the albino locus. Proc. Natl. Acad. Sci. 85: 1161-1164.

DeFranco, D., D. Bali, R. Torres, R.A. DePinho, R.P. Erickson, and S. Gluecksohn-Waelsch. 1991. The glucocorticoid hormone signal transduction pathway in mice homozygous for chromosomal deletions causing failure of cell type-specific inducible gene expression. Proc. Natl. Acad. Sci. 88: 56075610.

Dehner, L.P., D.C. Snover, H.L. Sharp, N. Ascher, R. Nakhleh, and D.L. Day. 1989. Hereditary tyrosinemia type I/chronic form): Pathological findings in liver. Hum. Pathol. 20: 149158.

Erickson, R.P., S. Gluecksohn-Waelsch, and C. Cori 1968. Glucose-6-phosphatase deficiency caused by radiation-induced alleles at the albino locus in the mouse. Proc. Natl. Acad. Sci. 59: 437-444.

Fornace, A.J. Jr., D.W. Nebert, M.C. Hollander, J.D. Luethy, M. Papathanasiou, J. Fargnoli, and N.J. Holbrook. 1989. Mammalian genes coordinately regulated by growth arrest signals and DNA-damaging agents. Mol. Cell. Biol. 9: 4196-4203.

Franke, W.W., M.R. Lüder, J. Kartenbeck, H. Zerban, and T.W. Keenan. 1976. Involvement of vesicle coat material in casein secretion and surface regulation. J. Cell Biol. 69: 173-195. 
Gluecksohn-Waelsch, S. 1979. Genetic control of morphogenetic and biochemical differentiation: Lethal albino deletions in the mouse. Cell 16: 225-237.

- 1987. Regulatory genes in development. Trends Genet. 3: 123-127.

Gluecksohn-Waelsch, S. and D. DeFranco. 1991. Lethal chromosomal deletions in the mouse, a model system for the study of development and regulation of postnatal gene expression. Bioessays 13: 557-561.

Goldsmith, L.A. and C. Laberge. 1989. Tyrosinemia and related disorders. In The metabolic basis of inherited disease, 6th ed. (ed. C.R. Scriver, A.L. Beaudet, W.S. Sly, and D. Valle), pp. 547-562. McGraw-Hill, New York.

Gonzalez, F.J., S.-Y. Liu, C.A. Kozak, and D.W. Nebert. 1990. Decreased Hnf-1 gene expression in mice homozygous for a 1.2-centiMorgan deletion on chromosome 7. DNA Cell Biol. 9: 771-776.

Hogan, B.L.M., F. Costantini, and E. Lacy. 1986. Manipulating the mouse embryo. Cold Spring Harbor Laboratory, Cold Spring Harbor, New York.

Holdener-Kenny, B., S.K. Sharan, and T. Magnuson. 1992. Mouse albino-deletions: From genetics to genes in development. Bioessays 14: 831-839.

Jantzen, H.-M., U. Strähle, B. Gloss, F. Stewart, W. Schmid, M. Boshart, R. Miksicek, and G. Schütz. 1987. Cooperativity of glucocorticoid response elements located far upstream of the tyrosine aminotransferase gene. Cell 49: 29-38.

Johnson, R.S., B.M. Spiegelman, and V. Papaioannou. 1992. Pleiotropic effects of a null mutation in the c-fos proto-oncogene. Cell 71: 577-586.

Jonat, C., H.J. Rahmsdorf, K-K. Park, A.C.B. Cato, S. Gebel, H. Ponta, and P. Herrlich. 1990. Antitumor promotion and antiinflammation: Down-modulation of AP-1 (Fos/Jun) activity by glucocorticoid hormone. Cell 62: 1189-1204.

Kastan, M.B., Q. Zhan, W.S. El-Deiry, F. Carrier, T. Jacks, W.V. Walsh, B.S. Plunkett, B. Vogelstein, and A.J. Fornace Jr. 1992. A mammalian cell cycle checkpoint pathway utilizing p53 and GADD45 is defective in Ataxia-Telengiectasia. Cell 71: 587-597.

Kelsey, G. and G. Schütz. 1993. Lessons from lethal albino mice. Curr. Opin. Genet. Develop. 3: 259-264.

Kelsey, G.D., S. Povey, A.E. Bygrave, and R.H. Lovell-Badge. 1987. Species- and tissue-specific expression of human $\alpha_{1}$ antitrypsin in transgenic mice. Genes \& Dev. 1: 161-171.

Kelsey, G.D., M. Parkar, and S. Povey. 1988. The human alpha1-antitrypsin-related sequence gene: Isolation and investigation of its expression. Ann. Hum. Genet. 752: 151-160.

Kelsey, G., A. Schedl, S. Ruppert, L. Niswander, T. Magnuson, M.L. Klebig, E.M. Rinchik, and G. Schütz. 1992. Physical mapping of the albino-deletion complex in the mouse to localize alf/hsdr-1, a locus required for neonatal survival. Genomics 14: 275-287.

Klebig, M.L., L.B. Russell, and E.M. Rinchik. 1992. Murine fumarylacetoacetate hydrolase $(F a h)$ gene is disrupted by a neonatally lethal albino deletion that defines the hepatocyte-specific developmental regulation 1 (hsdr-1) locus. Proc. Natl. Acad. Sci. 89: 1363-1367.

Kvittingen, E.A. 1986. Hereditary tyrosinemia type I: An overview. Scand. J. Clin. Lab. Invest. 46: 27-34.

Laberge, C., A. Lescault, A. Grenier, J. Morrisette, R. Gagné, P. Gadbois, and J. Halket. 1990. Oral loading of homogentisic acid in controls and in obligate heterozygotes for hereditary tyrosinemia type I. Am. J. Hum. Genet. 47: 329-337.

Leakey, J.E.A. 1983. Ontogenesis. In Biological basis of detoxication (ed. J. Caldwell and W.B. Jakoby), pp. 77-103. Academic Press, New York.
Liang, H.-C.L., H.G. Shertzer, and D.W. Nebert. 1992. "Oxidative stress" response in liver of an untreated newborn mouse having a 1.2-centiMorgan deletion on chromosome 7. Biochem. Biophys. Res. Commun. 182: 1160-1165.

Loose, D.S., P.A. Shaw, K.S. Krauter, C. Robinson, S. Englard, R.W. Hanson, and S. Gluecksohn-Waelsch. 1986. Transregulation of the phosphoenolpyruvate carboxykinase (GTP) gene, identified by deletions in chromosome 7 of the mouse. Proc. Natl. Acad. Sci. 83: 5184-5188.

McKnight, S.L., M.D. Lane, and S. Gluecksohn-Waelsch. 1989. Is CCAAT/enhancer-binding protein a central regulator of energy metabolism? Genes \& Dev. 3: 2021-2024.

Miyai, K. 1979. Ultrastructural basis for toxic liver injury. In Toxic injury of the liver (ed. E. Farber and M.M. Fisher), part A, pp. 59-130. Marcel Dekker, New York.

Morris S.M. Jr., C.L. Moncman, D.M. Kepka, V.L. Nebes, W.F. Diven, G.J. Dizikes, S.D. Cederbaum, and D. DeFranco. 1988. Effects of deletions in mouse chromosome 7 on expression of genes encoding the urea-cycle enzymes and phosphoenolpyruvate carboxykinase (GTP) in liver, kidney, and intestine. Biochem. Genet. 26: 769-781.

Müller, G., S. Ruppert, E. Schmid, and G. Schütz. 1988. Functional analysis of alternatively spliced tyrosinase gene transcripts. EMBO /. 7: 2723-2730.

Murphy, D., P.M. Brickell, D.S. Latchman, K. Willison, and P.W.J. Rigby. 1983. Transcripts regulated during normal embryonic development and oncogenic transformation share a repetitive element. Cell 35: 865-871.

Nebert, D. W., D.D. Petersen, and A.J. Fornace Jr. 1990. Cellular responses to oxidative stress: the $[A h]$ gene battery as a paradigm. Environ. Health Perspect. 88: 13-25.

Niswander, L., D. Yee, E.M. Rinchik, and T. Magnuson. 1989. The albino-deletion complex in the mouse defines genes necessary for development of embryonic and extraembryonic ectoderm. Development 105: 175-182.

Nitsch, D., M. Boshart, and G. Schütz. 1993. Activation of the tyrosine aminotransferase gene is dependent upon synergy between liver-specific and hormone-responsive elements. Proc. Nat1. Acad. Sci. 90: 5479-5483.

Petersen, D.D., F.J. Gonzalez, V. Rapic, C.A. Kozak, J.-Y. Lee, J.E. Jones, and D.W. Nebert. 1989. Marked increase in hepatic $\mathrm{NAD}(\mathrm{P} \mid \mathrm{H}$ :oxidoreductase gene transcription and mRNA levels correlated with a mouse chromosome 7 deletion. Proc. Natl. Acad. Sci. 86: 6699-6703.

Phaneuf, D., M. Lambert, R. Laframboise, G. Mitchell, F. Lettre, and R.M. Tanguay. 1992. Type 1 hereditary tyrosinemia. Evidence for molecular heterogeneity and identification of a causal mutation in a French Canadian patient. $/$. Clin. Invest. 90: 1185-1192.

Rinchik, E.M. and L.B. Russell. 1990. Germ-line deletion mutations in the mouse: Tools for intensive functional and physical mapping of regions of the mammalian genome. In Genetic and physical mapping. Genome Analysis (ed. K.E. Davies and S.M. Tilghman), vol. I, pp. 121-158. Cold Spring Harbor Laboratory Press, Cold Spring Harbor, New York.

Ron, D. and J.F. Habener. 1992. CHOP, a novel developmentally regulated nuclear protein that dimerizes with transcription factors C/EBP and LAP and functions as a dominant negative inhibitor of gene transcription. Genes \& Dev. 6: 439453.

Ruiz-Bravo, N. and M.J. Ernest. 1982. Induction of tyrosine aminotransferase mRNA by glucocorticoids and cAMP in fetal rat liver. Proc. Natl. Acad. Sci. 79: 365-368.

Ruppert, S., G. Müller, B. Kwon, and G. Schütz. 1988. Multiple transcripts of the mouse tyrosinase gene are generated by alternative splicing. EMBO J. 7: 2715-2722. 
Ruppert, S., M. Boshart, F.X. Bosch, W. Schmid, R.E.K. Fournier, and G. Schütz. 1990. Two genetically defined trans-acting loci coordinately regulate overlapping sets of liver-specific genes. Cell 61: 895-904.

Ruppert, S., G. Kelsey, A. Schedl, E. Schmid, E. Thies, and G. Schütz. 1992. Deficiency of an enzyme of tyrosine metabolism underlies altered gene expression in newborn liver of lethal albino mice. Genes \& Dev. 6: 1430-1443.

Russell, L.B., W.L. Russell, and E.M. Kelly. 1979. Analysis of the albino-locus region of the mouse. I. Origin and viability. Genetics 91: 127-139.

Russell, L.B., C.S. Montgomery, and G.D. Raymer. 1982. Analysis of the albino-locus region of the mouse. IV. Characterization of 34 deficiencies. Genetics 100: 427-453.

Russo, P. and S. O'Regan. 1990. Visceral pathology of hereditary tyrosinemia type I. Am. J. Hum. Genet. 47: 317-324.

Rüther, U., M. Tripodi, R. Cortese, and E.F. Wagner. 1987. The human alpha-1-antitrypsin gene is efficiently expressed from two tissue-specific promoters in transgenic mice. Nucleic Acids Res. 15: 7519-7529.

Schedl, A., S. Ruppert, G. Kelsey, E. Thies, L. Niswander, T. Magnuson, M.L. Klebig, E.M. Rinchik, and G. Schütz. 1992. Chromosomal jumping from flanking markers defines the minimal region for $a l f / h s d r-1$ within the albino-deletion complex. Genomics 14: 288-297.

Schmid, W., G. Müller, G. Schütz, and S. Gluecksohn-Waelsch. 1985. Deletions near the albino locus on chromosome 7 of the mouse affect the level of tyrosine aminotransferase mRNA. Proc. Natl. Acad. Sci. 82: 2866-2869.

Shelly, L.L., K.-J. Lei, C.-J. Pan, S.F. Sakata, S. Ruppert, G. Schütz, and J.Y. Chou. 1993. Isolation of the gene for murine glucose-6-phosphatase, the enzyme deficient in glycogen storage disease type 1A. J. Biol. Chem. (in press).

Sifers, R.N., J.A. Carlson, S.M. Clift, F.J. DeMayo, D.W. Bullock, and S.L.C. Woo. 1987. Tissue-specific expression of the human $\alpha$-1-antitrypsin gene in transgenic mice. Nucleic Acids Res. 15: 1459-1475.

Sladek, F.M., W. Zhong, E. Lai, and J.E. Darnell Jr. 1990. Liverenriched transcription factor HNF-4 is a novel member of the steroid hormone receptor superfamily. Genes \& Dev. 4: 2353-2365.

Talalay, P., M.J. De Long, and H.J. Prochaska. 1988. Identification of a common chemical signal regulating the induction of enzymes that protect against chemical carcinogenesis. Proc. Natl. Acad. Sci. 85: 8261-8265.

Tanguay, R.M., J.P. Valet, A. Lescault, J.L. Duband, C. Laberge, F. Lettre, and M. Plante. 1990. Different molecular basis for fumarylacetoacetate hydrolase deficiency in the two clinical forms of hereditary tyrosinemia (type I). Am. I. Hum. Genet. 47: 308-316.

Tönjes, R.R., K.G. Xanthopoulos, J.E. Darnell Jr., and D. Paul. 1992. Transcriptional control in hepatocytes of normal and c14CoS albino deletion mice. EMBO J. 11: 127-133.

Tremblay, M., L. Bélanger, J. Larochelle, L. Privé, and P.M. Gagnon. 1977. Tyrosinémie héréditaire: Examen du foie en microscopie électronique de biopsies hépatiques: Observation de sept cas. L'Union Méd. du Canada 106: 1014-1016.

Trigg, M.J. and S. Gluecksohn-Waelsch. 1973. Ultrastructural basis of biochemical effects in a series of lethal alleles in the mouse. I. Cell Biol. 58: 549-563.

Wang, Z.-Q., C. Ovett, A.E. Grogoriandis, U. Möhle-Steinlein, U. Rüther, and E.F. Wagner. 1992. Bone and haematopoeitic defects in mice lacking c-fos. Nature 360: 741-745.

Yang-Yen, H.-F., J.-C. Chambard, Y.-L. Sun, T. Smeal, T.J. Schmidt, J. Drouin, and M. Karin. 1990. Transcriptional interference between $\mathrm{c}$-Jun and the glucocorticoid receptor:
Mutual inhibition of DNA binding due to direct proteinprotein interaction. Cell 62: 1205-1215.

Zaret, K.S., P. Milos, M. Lia, D. Bali, and S. GluecksohnWaelsch. 1992. Selective loss of a DNase I hypersensitive site upstream of the tyrosine aminotransferase gene in mice homozygous for lethal albino deletions. Proc. Natl. Acad. Sci. 89: 6540-6544. 


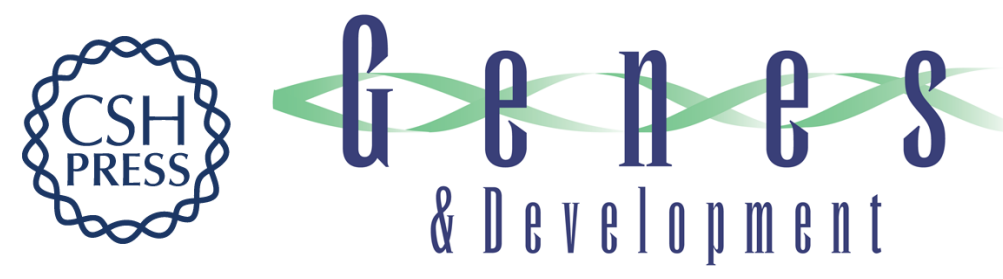

\section{Rescue of mice homozygous for lethal albino deletions: implications for an animal model for the human liver disease tyrosinemia type 1.}

G Kelsey, S Ruppert, F Beermann, et al.

Genes Dev. 1993, 7:

Access the most recent version at doi:10.1101/gad.7.12a.2285

References This article cites 58 articles, 21 of which can be accessed free at:

http://genesdev.cshlp.org/content/7/12a/2285.full.html\#ref-list-1

License

Email Alerting

Receive free email alerts when new articles cite this article - sign up in the box at the top

Service right corner of the article or click here.

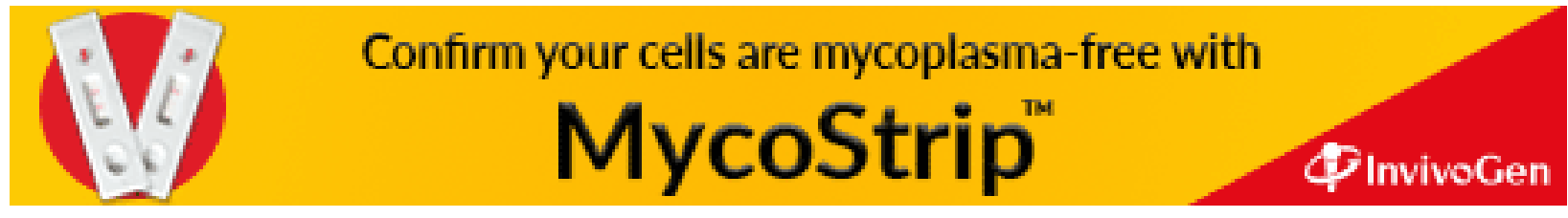

